\title{
Controle da pinta preta dos frutos cítricos em cultivo orgânico com agentes de biocontrole e produtos alternativos
}

\author{
Eduardo Roberto A. Bernardo ${ }^{1}$ \& Wagner Bettiol ${ }^{2}$ \\ ${ }^{1}$ Departamento de Proteção de Plantas, Faculdade de Ciências Agronômicas, Universidade Estadual Paulista - UNESP, \\ 18610-307, Botucatu, SP, Brasil; ${ }^{2}$ Embrapa Meio Ambiente, 13820-000, Jaguariúna, SP, Brasil
}

Autor para correspondência: Wagner Bettiol, e-mail: bettiol@cnpma.embrapa.br

\begin{abstract}
RESUMO
Bacillus subtilis, Trichoderma harzianum e leite foram avaliados no controle da pinta preta de laranja 'Pêra' orgânica, nas safras 2004/2005 e 2005/2006. Os tratamentos estudados foram: Bacillus $\left(10^{7}\right.$ e $10^{8}$ ufc/mL), meio de cultura para fermentação de Bacillus, Trichoderma $\left(10^{6}\right.$ conídios $\left./ \mathrm{mL}\right)$, leite $(5 \%)$ e testemunha(biofertilizantea $\left.3 \%\right)$. Os produtos, excetobiofertilizante(pulverizadomensalmente), foram pulverizados 28, 56, 84, 112, 140 e 168 dias depois da primeira pulverização (08/12/2004 e 09/12/2005, respectivamente). A severidade da doença foi avaliada utilizando escala de notas de 1 a 6 em 50 frutos/repetição. Na safra 2004/2005, as plantas pulverizadas com leite e Bacillus $\left(10^{8} \mathrm{ufc} / \mathrm{mL}\right)$ apresentaram maior número de frutos com nota 1 (26,3 e 19,4\%, respectivamente) e menor com notas de 3 a 6 (29,8 e 35,6\%, respectivamente). Na safra 2005/2006, o maior número de frutos com nota 1 (7,4 e 3,7\%) e o menor na faixa de 3 a $6(64,4$ e $71,0 \%)$ foram observados nas plantas pulverizadas com leite e Bacillus $\left(10^{7} \mathrm{ufc} / \mathrm{mL}\right)$, respectivamente. O índice de doença (ID), na safra 2004/2005, foi de 0,36 para os tratamentos com leite e Bacillus $10^{8} \mathrm{ufc} / \mathrm{mL}$, e de 0,43 para o tratamento com biofertilizante. Em 2005/2006, os IDs foram 0,51; 0,53 e 0,53 para os tratamentos leite, Bacillus $10^{7} \mathrm{ufc} / \mathrm{mL}$ e biofertilizante, respectivamente. As plantas tratadas com Trichoderma apresentaram IDs de 0,47 e 0,58 nas safras 2004/2005 e 2005/2006, respectivamente.
\end{abstract}

Palavras-chave: Guignardia citricarpa, mancha preta dos frutos cítricos, controle alternativo, controle biológico, chá de composto.

\begin{abstract}
Biocontrol and alternative products for managing citrus black spot in organic cropping systems

Bacillus subtilis, Trichoderma harzianum, and milk were evaluated in 2004/2005 and 2005/2006 cropping seasons to control citrus black spot in organic systems. The treatments studied were: Bacillus $\left(10^{7}\right.$ and $\left.10^{8} \mathrm{cfu} / \mathrm{mL}\right)$, media for the fermentation of Bacillus, Trichoderma $\left(10^{6}\right.$ conidia/mL), milk $(5 \%)$ and check (compost tea 3\%). The products, except compost tea (sprayed monthly), were sprayed at scheduled intervals $\left(28,56,84,112,140\right.$, and 168 days) starting on December $8^{\text {th }}, 2004$ and December $9^{\text {th }}, 2005$. Disease severity was evaluated by a six-category scale in 50 fruits. In 2004/2005, plants sprayed with milk and Bacillus (10 $\mathrm{cfu} / \mathrm{mL}) \mathrm{did}$ not differ from each other. These treatments presented an increase in the percentage of fruits in class $1(26.3 \%$ and $19.4 \%$, respectively), and a decrease in the percentage of fruits in class 3-6 (29.9\% and 35.6\%, respectively). In 2005/2006, spraying milk and Bacillus (107 cfu/mL) resulted in the highest percentage of fruits in class 1 (7.4 and 3.7\%, respectively) and the lowest percentage of fruits in class 3-6 (64.4 and $71.0 \%$, respectively). Plants treated with milk and Bacillus $10^{8} \mathrm{cfu} / \mathrm{mL}$ had less disease during 2004/2005, with disease index (DI) $=0.36$, compared to DI of 0.43 for compost tea. In 2005/2006, values of DI in treatments with milk, Bacillus $10^{7}$ cfu/mL and compost tea were $0.51,0.53$, and 0.53 , respectively. The values of DI in plants sprayed with Trichoderma were 0.47 and 0.58 , respectively for $2004 / 2005$ and 2005/2006.
\end{abstract}

Keywords: Guignardia citricarpa, citrus black spot, alternative control, biological control, compost tea.

\section{INTRODUÇÃO}

A pinta preta dos citros, causada por Guignardia citricarpa Kiely, é responsável por consideráveis perdas em citros cultivados no estado de São Paulo. Causa a queda prematura dos frutos com severas reduções de produtividade. Os sintomas restringem-se ao flavedo, não alterando a qualidade dos frutos, sendo possível sua utilização na produção de suco concentrado (AguilarVildoso et al., 2002). O controle da doença baseia-se na aplicação de fungicidas protetores, sistêmicos ou a mistura deles, associados a óleos minerais ou vegetais (Goes,
2002). Segundo Goes (1998), os melhores resultados são obtidos com intervalos de pulverizações de 50 ou 55 dias com a mistura de fungicidas sistêmicos e protetores, e de 28 dias utilizando somente fungicidas protetores. Entretanto, problemas relacionados ao uso de fungicidas, como o surgimento de isolados de G. citricarpa resistentes a carbendazim (Rodrigues et al., 2007), impactos negativos ao ambiente e restrições de ordem pública e econômica estimulam a busca de novas alternativas de controle de doenças, principalmente pela introdução de agentes de biocontrole e de produtos alternativos. Além disso, para o cultivo orgânico, cuja procura por produtos é crescente, 
os problemas com essa doença são grandes, havendo necessidade de desenvolvimento de produtos alternativos.

Dentre os microrganismos mais estudados para o controle biológico de doenças encontram-se espécies do gênero Trichoderma e Bacillus subtilis (Ehrenberg) Cohn (Bettiol et al., 1994, 2009; Kupper \& Fernandes, 2002; Kupper et al., 2003; Prasad et al., 2002). Outra opção econômica e de baixo impacto ambiental é o uso de extratos aquosos de matéria orgânica ebiofertilizantes. Esses produtos possuem uma complexa e elevada comunidade microbiana, com presença de bactérias e fungos leveduriformes e filamentosos (McQuilken et al., 1994; Elad \& Shtienberg, 1994; Yohalem et al., 1996; Tratch \& Bettiol, 1997; Kupper et al., 2006). A principal vantagem desta técnica é o custo, pois o agricultor não depende da compra do material, mas sim do aproveitamento de material orgânico disponível na propriedade. O presente trabalho teve por objetivo avaliar o efeito de agentes de controle biológico e de produtos alternativos no controle da pinta preta dos citros em laranja 'Pêra' cultivada no sistema orgânico.

\section{MATERIAL E MÉTODOS}

\section{Produtos alternativos}

Os agentes de biocontrole foram obtidos da coleção de culturas da Embrapa Meio Ambiente. Para multiplicação de Bacillus subtilis (AP3), a partir de culturas puras mantidas em placas contendo nutriente-ágar (NA), colônias foram raspadas com alça e a suspensão obtida foi transferida para Erlenmeyer contendo $500 \mathrm{~mL}$ de Batata-Dextrose (BD). O Erlenmeyer foi mantido em agitação a $180 \mathrm{rpm} / \mathrm{min}$ e temperatura ambiente por $72 \mathrm{~h}$. Decorrido esse período, $100 \mathrm{~mL}$ do caldo fermentado foram transferidos para outros Erlenmeyers contendo $400 \mathrm{~mL}$ de BD, que foram submetidos às mesmas condições descritas. Para a fermentação em maior escala, foi utilizado um fermentador com capacidade de 50 L com injeção de ar, contendo meio constituído de água, melaço de cana-de-açúcar $(0,5 \% \mathrm{v} / \mathrm{v})$, milhocina $(0,5 \% \mathrm{v} / \mathrm{v})$ e fosfato monobásico $(0,3 \% \mathrm{p} / \mathrm{v})$, autoclavado por $40 \mathrm{~min}$ a 1,5 atm. Ao meio foi transferida a suspensão da bactéria, anteriormente preparada, na proporção de $10 \%$ do volume e mantido sob aeração por $72 \mathrm{~h}$ para a fermentação.

Trichoderma harzianum Rifai, isolado T01BA, foi multiplicado em meio sólido (400 g de grãos de arroz e 170 $\mathrm{mL}$ de água) previamente autoclavado por $20 \mathrm{~min}$ a $120^{\circ} \mathrm{C}$ e $1,2 \mathrm{~atm}$ em sacos de polipropileno $(25 \times 35 \mathrm{~cm})$. Após o resfriamento, ao meio foi transferida uma suspensão com 1 x $10^{4}$ conídios $/ \mathrm{mL}$ com auxílio de seringa bovina. Após 7 a 10 dias de incubação a $25 \pm 2^{\circ} \mathrm{C}$ os sacos de polipropileno contendo o fungo foram acondicionados em câmara fria $\left(3^{\circ} \mathrm{C}\right)$ por até 120 dias.

O biofertilizante foi fornecido pela Microbiol Indústria e Comércio Ltda. (Limeira, SP) $(\mathrm{pH}=6,5$; $\mathrm{MO}=0,52 \% ; \mathrm{N}=1,05 \%, \mathrm{C} / \mathrm{N}=<1 ; \mathrm{P}=115 \mu \mathrm{g} / \mathrm{L} ; \mathrm{K}=362 \mu \mathrm{g} /$ $\mathrm{L} ; \mathrm{Ca}=60 \mu \mathrm{g} / \mathrm{L} ; \mathrm{Mg}=75 \mu \mathrm{g} / \mathrm{L} ; \mathrm{S}=400 \mu \mathrm{g} / \mathrm{L} ; \mathrm{Na}=175 \mu \mathrm{g} / \mathrm{L})$ e analisado quanto à comunidade microbiana. Para tanto, uma amostra foi coletada em garrafa PET esterilizada e mantida a $8 \pm 2^{\circ} \mathrm{C}$ por $24 \mathrm{~h}$. Da amostra foi retirada uma alíquota de $10 \mathrm{~mL}$ e realizada diluição em série em água destilada e esterilizada. As suspensões foram transferidas para placas contendo os meios NA, King B, Martin e amido-caseína-ágar para a quantificação de bactérias totais e Bacillus, Pseudomonas spp., fungos e actinobactérias, respectivamente. No caso específico de Bacillus, as amostras foram submetidas a tratamento térmico a $80^{\circ} \mathrm{C}$ por 20 min em banho-maria, antes do plaqueamento.

\section{Controle da pinta preta em cultivo orgânico com os produtos alternativos}

$\mathrm{O}$ experimento foi conduzido durante as safras 2004/2005 e 2005/2006 em pomar de laranja 'Pêra' enxertada em limão cravo com 20 anos, localizado em Santa Eudóxia, SP, com histórico da pinta preta dos citros e cultivado desde o seu início no sistema orgânico. Para as avaliações, foram utilizadas as mesmas plantas em ambas as safras. Os produtos foram aplicados com pulverizador tratorizado, sendo o volume de calda calibrado para atingir o início do ponto de escorrimento (aproximadamente $12 \mathrm{~L} /$ planta). As árvores foram pulverizadas em intervalos de 28 dias, sendo o início em 08/12/2004, para a safra 2004/2005 e 09/12/2005, para a safra 2005/2006, exceto para o tratamento com biofertilizante, que foi mensal, pois é prática rotineira na propriedade e foi considerado o tratamento testemunha no estudo. As concentrações de B. subtilis foram $10^{7}$ e $10^{8} \mathrm{ufc} / \mathrm{mL}$, a de $T$. harzianum foi de $10^{6}$ conídios $/ \mathrm{mL}$ e a de leite cru foi de $5 \%$. Além desses, foi incluído um tratamento contendo o meio de cultivo utilizado para a fermentação de Bacillus (0,5\% de milhocina, $0,5 \%$ de melaço e $0,3 \%$ de fosfato monobásico). O delineamento experimental foi o inteiramente casualizado com 15 repetições, sendo a parcela representada por uma planta.

As avaliações foram realizadas em 50 frutos coletados ao acaso em cada planta. Esses frutos foram pesados e submetidos à avaliação da severidade, utilizando-se a escala diagramática de Spósito et al. (2004) para mancha dura: 1 - 0,5\%; 2- 1,7\%; 3 - 5,0\%; 4 - 11,5\%; 5 - 22,5\%; e 6 - 49,0\% de área lesionada. Com esses dados foram calculados os índices de doença (ID) utilizando a fórmula $(\mathrm{ID}=\mathrm{Fv} / \mathrm{nX}$, na qual $\mathrm{F}=$ número de frutos; $\mathrm{v}=$ nota; $\mathrm{n}=$ número total de frutos avaliados; $\mathrm{X}=$ número de classes de notas). Além disso, foi calculada a porcentagem de frutos classificados nas classes 1,2 e de 3 a 6 .

Para o ano agrícola 2005/2006 também foi avaliada a decomposição de folhas cítricas, que são a principal fonte de inóculo de G. citricarpa (Baldassari et al., 2006). A avaliação da taxa de decomposição foi feita pela análise de perda de massa utilizando-se "litter bags", segundo metodologia de Fernandes et al. (2006), modificando-se o diâmetro da malha para $0,5 \times 0,5 \mathrm{~cm}$ e dimensões de $60 \times 40 \mathrm{~cm}$. Em cada "litter bag" foram adicionadas $100 \mathrm{~g}$ de folhas cítricas verdes e maduras. Os "litter bags" foram distribuídos sob a projeção das copas de plantas adultas, simulando a queda natural do material formador da serapilheira. Os "litter bags", fixados ao solo com auxílio de grampos metálicos, foram instalados em 
08/12/2005 e coletados aos 60, 120 e 180 dias. Após a coleta, o conteúdo dos "litter bags" foi seco em estufa de circulação de ar forçada $\left(65 \pm 5^{\circ} \mathrm{C}\right)$ até atingir peso constante. Em laboratório o conteúdo foi examinado para retirada de partículas de solo e, posteriormente, sua massa foi determinada. A taxa de decomposição da serapilheira foi quantificada mediante avaliação de medida da perda de massa (Fernandes et al., 2006), com a seguinte fórmula: Massa remanescente $(\%)=$ (massa final/ massa inicial) x 100. Os dados foram submetidos à análise de variância e as médias foram comparadas pelo teste de Tukey a 5\% de probabilidade, utilizando-se o programa SAS (2002). Análise de regressão foi utilizada para a decomposição de folhas.

\section{RESULTADOS E DISCUSSÃO}

A comunidade microbiana encontrada nos biofertilizantes é variável e depende do processo (aeróbio ou anaeróbio) e do substrato utilizado na sua produção. $\mathrm{O}$ biofertilizante apresentou a carga microbiana composta principalmente por bactérias $\left(3 \times 10^{6} \mathrm{ufc} / \mathrm{mL}\right)$, sendo na sua maioria Bacillus spp. (3,2 × $\left.10^{5} \mathrm{ufc} / \mathrm{mL}\right)$, Pseudomonas spp. $\left(1,5 \times 10^{4} \mathrm{ufc} / \mathrm{mL}\right)$ e, em menor escala, actinobactérias $(1,1$ x $10^{2} \mathrm{ufc} / \mathrm{mL}$ ), que são organismos estudados para o controle biológico de diversas doenças de plantas (Janisiewicz \& Jeffers, 1997; Sales Júnior et al., 2007). Os dados populacionais encontrados no biofertilizante diferem dos encontrados por Kupper et al. (2006), que comparando dois biofertilizantes, encontraram populações de bactérias totais da ordem de $1,29 \times 10^{5}$ ufc $/ \mathrm{mL}$ e Bacillus spp. de 3,6 × $10^{4} \mathrm{ufc} / \mathrm{mL}$. A comunidade de fungos do biofertilizante foi de 5,5 $\times 10^{5}$ $\mathrm{ufc} / \mathrm{mL}$.

Os valores de ID calculados para as safras 2004/2005 e $2005 / 2006$ foram, respectivamente, para as plantas pulverizadas com B. subtilis $10^{7}(0,40$ e 0,53$)$, B. subtilis $10^{8}(0,36$ e 0,57$)$, T. harzianum $(0,47$ e 0,58$)$, meio de cultura para fermentação de Bacillus $(0,43$ e 0,57), biofertilizante=testemunha $(0,43$ e $0,53)$ e o leite $(0,36$ e 0,51$)$ (Figura $1 \mathrm{AB})$. Considerando que Kupper et al. (2006) verificaram $\mathrm{ID}=0,217$ para o controle da pinta preta nas árvores pulverizadas com oxicloreto de cobre + carbendazim + mancozeb pode-se considerar que os produtos testados foram pouco eficientes no controle da doença. Entretanto, deve ser considerado que não existe tratamento padrão para o controle da doença em cultivo orgânico. Para a safra 2004/2005, os tratamentos com Bacillus $\left(10^{8} \mathrm{ufc} / \mathrm{mL}\right)$ e leite (5\%), apesar de não diferirem estatisticamente do tratamento com biofertilizante, utilizado como testemunha no estudo, apresentaram menor ID que o tratamento com T. harzianum (Figura 1). Por outro lado, na safra 2005/2006 apenas o tratamento com leite diferiu do com Trichoderma.
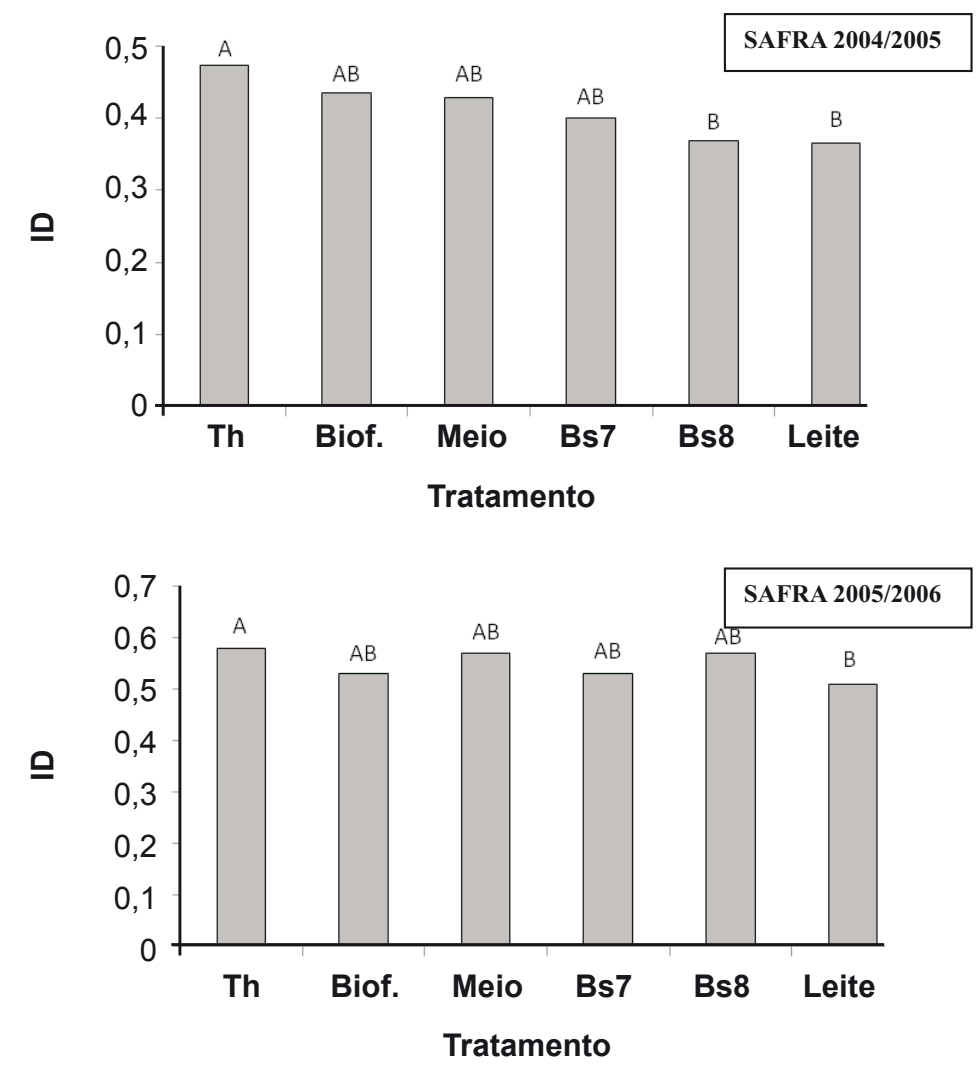

FIGURA 1 - Efeito do leite, Bacillus subtilis (Bs7 $\left.=10^{7} \mathrm{ufc} / \mathrm{mL} ; \mathrm{Bs} 8=10^{8} \mathrm{ufc} / \mathrm{mL}\right)$, meio de cultura para fermentação de Bacillus $(0,5 \%$ de melaço $+0,5 \%$ de milhocina e $0,3 \%$ de fosfato monobásico), Trichoderma harzianum $\left(\mathrm{Th}=10^{6}\right.$ conídios $/ \mathrm{mL}$ ) e biofertilizante como testemunha (Biof.) no índice de doença (ID) da pinta preta (Guignardia citricarpa) de laranja 'Pêra' orgânica. Médias seguidas pela mesma letra não diferem entre si (Tukey 5\%). Coeficientes de variação=18\% e $15 \%$, para a safra $2004-2005$ e 2005/2006, respectivamente. 
As plantas pulverizadas com leite e Bacillus $\left(10^{8}\right.$ $\mathrm{ufc} / \mathrm{mL}$ ) apresentaram, na safra 2004/2005, as maiores porcentagens de frutos pertencentes à nota $1(26,4$ e 19,5\%, respectivamente) e as menores porcentagens pertencentes às notas de 3 a $6(29,8$ e 35,6\%, respectivamente). Por outro lado, o tratamento testemunha com biofertilizante apresentou 11,0 e 50,8\%, respectivamente (Figura 2A), diferindo estatisticamente do tratamento com leite quando considerada a nota 1 e a faixa de notas de 3 a 6 . Na safra
2005/2006, as plantas pulverizadas com leite ou Bacillus $\left(10^{7} \mathrm{ufc} / \mathrm{mL}\right)$ apresentaram as maiores porcentagens de frutos pertencentes à nota 1 (7,4 e 3,7\%, respectivamente) e as menores porcentagem pertencentes às notas de 3 a 6 (64,4 e 71,0\%, respectivamente) (Figura 2B). Nessa safra, o tratamento testemunha com biofertilizante apresentou 2,3 e $76,7 \%$ de frutos com notas 1 e de 3 a 6 , respectivamente, diferindo estatisticamente do tratamento com leite quando considerada a nota 1 . Nas duas safras, as plantas pulverizadas

SAFRA 2004/2005

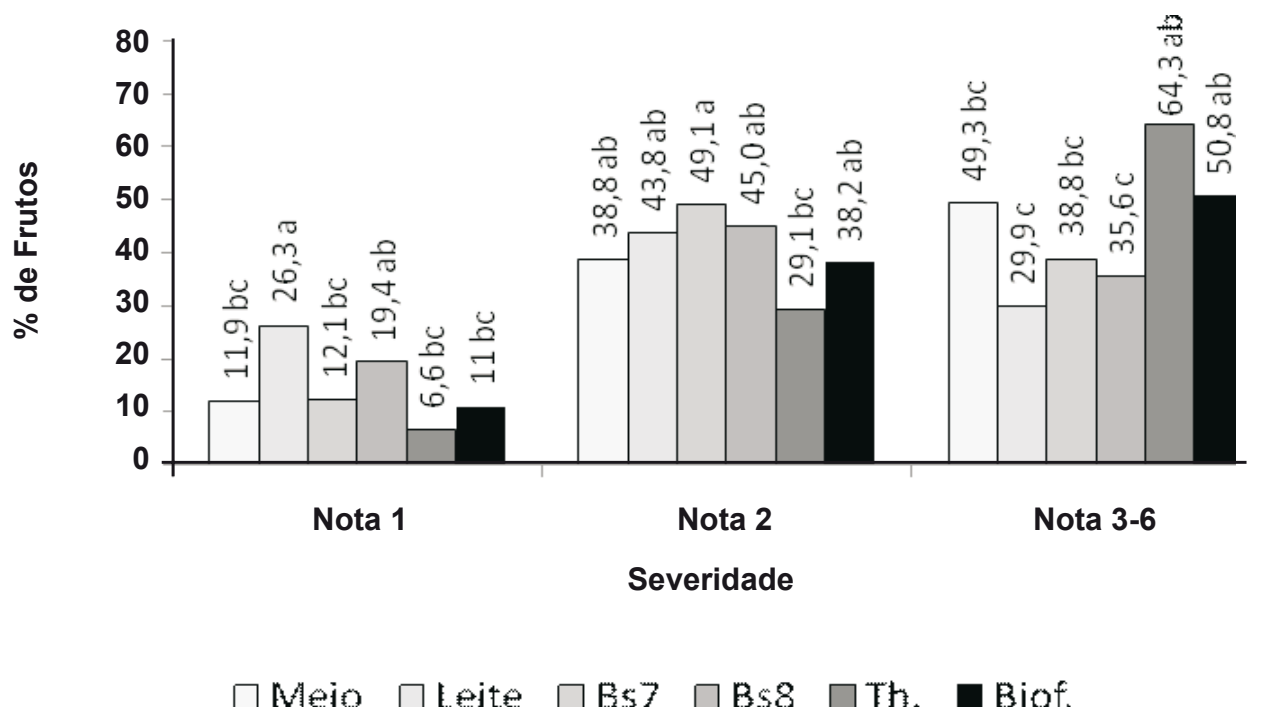

SAFRA 2005/2006

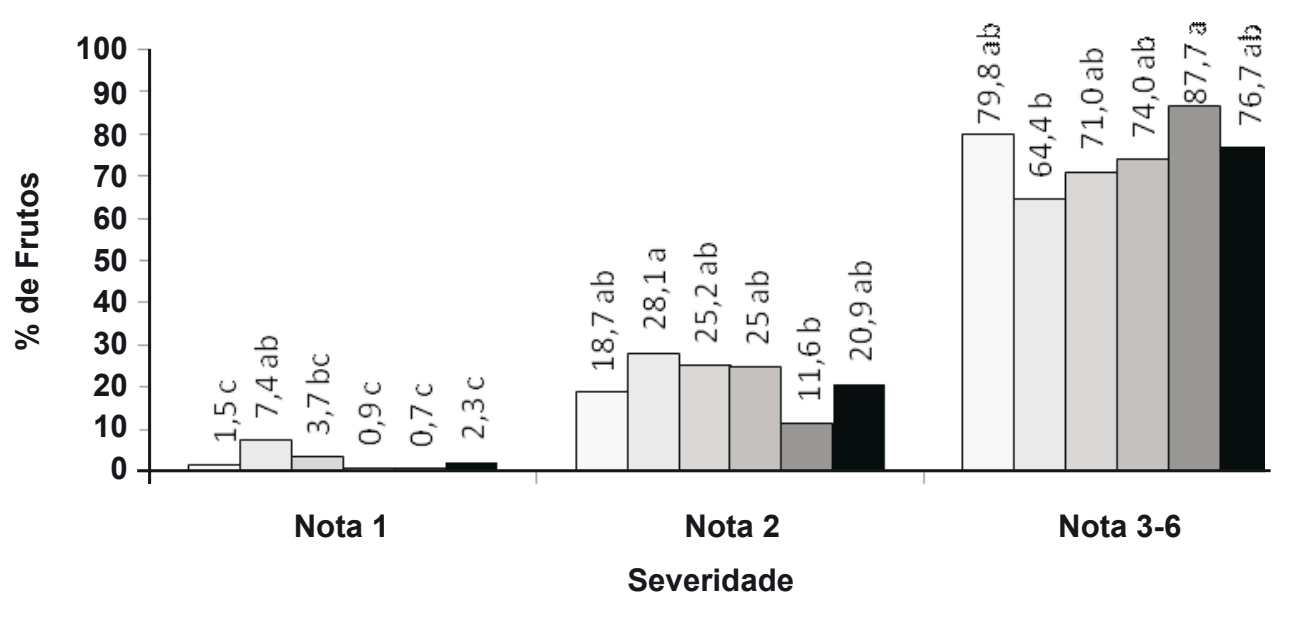

$\square$ Meio $\square$ Leite $\square$ Bs $\square$ Bs8 $\square$ Th. $\square$ Biof.

FIGURA 2 - Efeito do leite, Bacillus subtilis (Bs7 = $\left.10^{7} \mathrm{ufc} / \mathrm{mL} ; \mathrm{Bs} 8=10^{8} \mathrm{ufc} / \mathrm{mL}\right)$, meio de cultura para fermentação de Bacillus (0,5\% de melaço $+0,5 \%$ de milhocina e $0,3 \%$ de fosfato monobásico), Trichoderma harzianum $\left(\mathrm{Th}=10^{6}\right.$ conídios $/ \mathrm{mL}$ ) e biofertilizante como testemunha (Biof.) na porcentagem de frutas com notas 1, 2 e de 3 a 6 de severidade da pinta preta (Guignardia citricarpa) de laranja 'Pêra' orgânica. Médias, dentro das notas, seguidas pela mesma letra não diferem entre si (Tukey 5\%). 
com Trichoderma apresentaram a menor porcentagem de frutos com a nota 1 e a maior com frutos nas classes de 3 a $6(64,3$ e $87,7 \%$, respectivamente) (Figura 2B).

Apesar dos IDs do tratamento com leite não terem sido reduzidos significativamente nas duas safras em relação ao tratamento testemunha com biofertilizante (Figura $1 \mathrm{~A}$ B), os IDs foram inferiores aos demais tratamentos. Dessa forma, e considerando que no tratamento com leite houve um aumento significativo na porcentagem de frutos com nota 1 , nas duas safras, em relação aos demais tratamentos (Figura 2 A-B), esse é o primeiro relato do efeito desse produto em um patossistema não envolvendo oídio, pois o leite é apenas recomendado para o controle de oídio (Bettiol et al., 1999). Assim, há necessidade da realização de mais estudos com esse produto alternativo, inclusive para entender o seu modo de ação. Se for confirmada a eficiência do leite, esse produto apresenta ampla possibilidade de uso, pois a região citrícola do estado também é produtora expressiva de leite. Aliado a isso, poderiam ser testados os subprodutos da indústria láctea. Ainda seria importante que o leite e o Bacillus fossem testados em conjunto visando ao manejo da doença em sistema orgânico.

$\mathrm{O}$ fato de $T$. harzianum não ter sido eficiente no controle da doença indica que o fungo, originado do solo, não se adaptou ao ambiente da parte aérea das plantas ou que o isolado avaliado não é eficiente para o patossistema testado. B. subtilis tem se mostrado eficiente no controle de vários patógenos que ocorrem no filoplano, inclusive com diversos produtos comerciais disponíveis no mercado mundial (Bettiol et al., 2009). Segundo Knudsen \& Spurr Jr. (1986), a habilidade de bactérias formadoras de esporos permanecerem metabolicamente dormentes por longos períodos, aumenta sua sobrevivência na superfície foliar, possibilitando sua permanência em períodos secos, em temperaturas extremas e na deficiência temporária de nutrientes. Tal fato, provavelmente tenha colaborado para a eficiência de B. subtilis $\left(10^{8} \mathrm{ufc} / \mathrm{mL}\right)$ no controle da pinta preta na safra 2004/2005. Kupper et al. (2006) relatam que na África do Sul é comercializado um isolado de $B$. subtilis para o controle da pinta preta dos frutos cítricos, sendo esse o único relato de um produto biológico para o controle dessa doença. Além disso, Kupper et al. (2003) relataram que, em condições naturais, $B$. subtilis equiparou-se estatisticamente ao fungicida benomyl, proporcionando a menor porcentagem de flores com sintomas da queda prematura de frutos cítricos causada por Colletotrichum acutatum.

Em áreas de ocorrência da pinta preta, a decomposição das folhas cítricas caídas ao solo é de extrema importância, haja vista que dependendo da umidade, época do ano e do estádio de decomposição foliar, há liberação dos ascósporos, que é a principal fonte de inóculo do patógeno (Baldassari et al., 2006). Segundo Swift et al. (1979) e Aerts (1997), os três principais fatores que influenciam a decomposição, em ordem de importância, são as condições climáticas, composição química das folhas e os organismos presentes no solo, que são determinados pelo microclima. Neste trabalho, a taxa de decomposição manteve-se estável durante o período de avaliação, não sendo observadas diferenças estatísticas entre os tratamentos. Nos primeiros 60 dias, a degradação da massa foliar foi mais rápida, mantendo-se contínua até o final das avaliações (Figura 3).

A aplicação de leite e $B$. subtilis, apesar da eficiência de controle inferior às apresentadas para os fungicidas (Kupper et

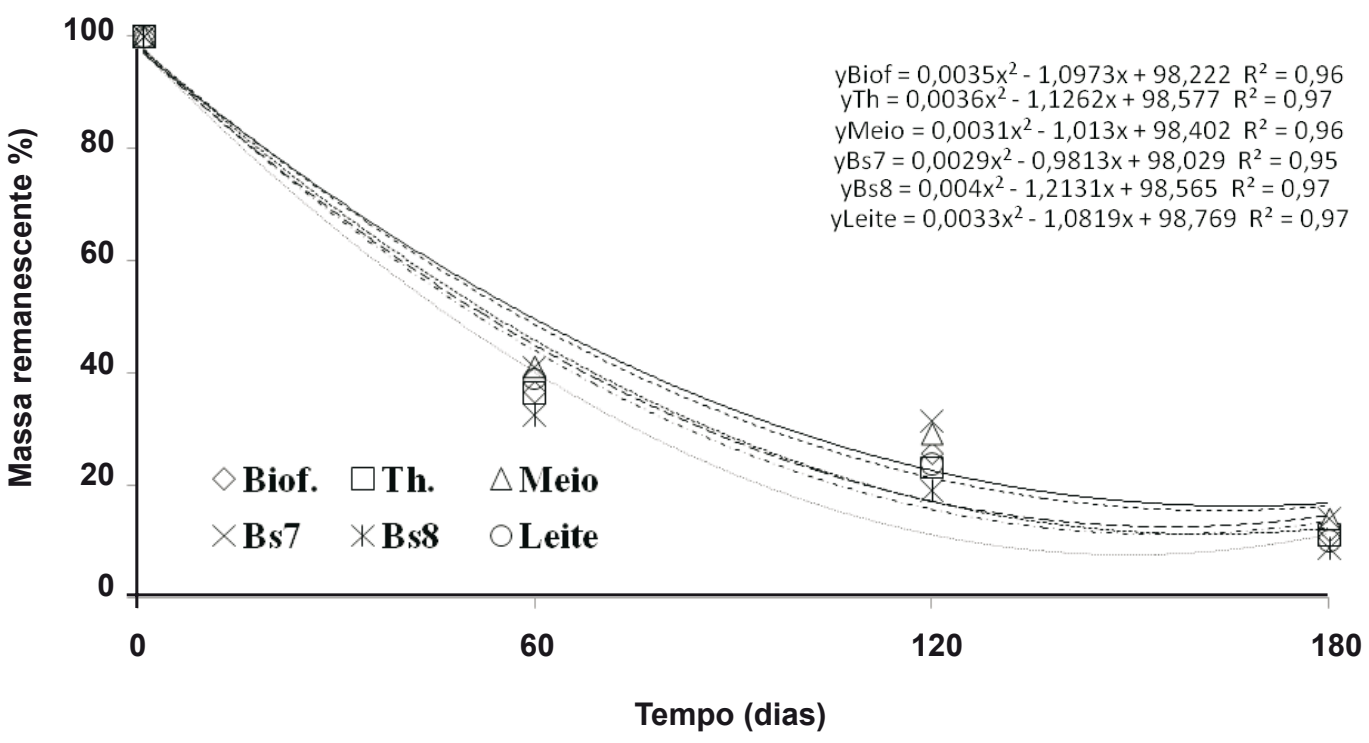

FIGURA 3 - Efeito do leite, Bacillus subtilis (Bs7 = $10^{7} \mathrm{ufc} / \mathrm{mL}$; Bs8 $=10^{8} \mathrm{ufc} / \mathrm{mL}$ ), meio de cultura para fermentação de Bacillus ( $0,5 \%$ de melaço $+0,5 \%$ de milhocina e $0,3 \%$ de fosfato monobásico), Trichoderma harzianum $\left(\mathrm{Th}=10^{6}\right.$ conídios $/ \mathrm{mL}$ ) e biofertilizante como testemunha (Biof.) na decomposição de folhas de laranja 'Pêra' orgânica. 
al., 2006), pode ser útil para o controle da pinta preta dos citros em sistema de produção orgânico. Para tanto, há necessidade de adequar principalmente à época de início, bem como a frequência das pulverizações, pois são produtos de contato e de baixa persistência no ambiente. Entretanto, existem evidências na literatura de potencial de uso de $B$. subtilis para plantas de ciclo longo e com doença que ocorre ao longo do período, como por exemplo, o controle da sigatoka-negra da bananeira e da antracnose em manga com um produto à base de B. subtilis (Edgecomb \& Manker, 2008).

\section{AGRADECIMENTOS}

Os autores agradecem ao Conselho Nacional de Desenvolvimento Científico e Tecnológico - CNPq pela concessão de bolsa de estudo e bolsa de produtividade, respectivamente.

\section{REFERÊNCIAS BIBLIOGRÁFICAS}

Aerts R (1997) Climate, leaf litter chemistry and leaf litter decomposition in terrestrial ecosystems: a triangular relationship. Oikos 79:439-449.

Aguilar-Vildoso CI, Ribeiro JGB, Feichtenberger E, Goes A, Spósito MB (2002) Manual Técnico de Procedimentos da Mancha Preta dos Citros. Brasília DF. MAPA/SDA/DDIV.

Baldassari RB, Reis RF, Goes A (2006) Susceptibility of fruits of the 'Valência' and 'Natal' sweet orange varieties to Guignardia citricarpa and the influence of the coexistence of healthy and symptomatic fruits. Fitopatologia Brasileira 31:337-341.

Bettiol W, Morandi MAB, Pinto ZV, Paula Junior TJ, Corrêa EB, Moura AB, Lucon CMM, Costa JCB, Bezerra JL (2009) Bioprotetores comerciais para o controle de doenças de plantas. Revisão Anual de Patologia de Plantas 17:111-147.

Bettiol W, Saito ML, Brandão MSB (1994) Controle da ferrugem do cafeeiro com produtos à base de Bacillus subtilis. Summa Phytopathologica 20:119-122.

Bettiol W, Astiarraga BD, Luiz AJB (1999) Effectiveness of cow's milk against zucchini squash powdery mildew (Sphaerotheca fuliginea) in greenhouse conditions. Crop Protection 18:489-492.

Edgecomb DW, Manker DC (2008) Serenade (Bacillus subtilis strain QST713) and Sonata (Bacillus pumilus strain QST2808), new biological tools for integrated and organic disease control programs. Summa Phytopathologica 34S:196-199.

Elad Y, Shtinberg D (1994) Effect of compost water extracts on grey mould (Botrytis cinerea). Crop Protection 13:109-114.

Fernandes MM, Pereira MG, Magalhães LMS, Cruz AR, Giácomo RG (2006) Aporte e decomposição de serapilheira em áreas de floresta secundária, plantio de sabiá (Mimosa caesalpiniaefolia Benth.) e andiroba (Carapa guianensis Aubl.) na Flona Mário Xavier, RJ. Ciência Florestal 16:163-175.
Goes A (1998) Controle da mancha-preta dos frutos cítricos. Laranja 19:305-320.

Goes A (2002) Efeito da combinação de fungicidas sistêmicos e protetores no controle da mancha preta dos frutos cítricos causados por Guignardia citricarpa. Summa Phytopathologica 28:9-13.

Janisiewicz WJ, Jeffers SN (1997) Efficacy of commercial formulation of two biofungicides for control of blue mold and gray mold of apples in cold storage. Crop Protection 16:629-633.

Knudsen GR, Spurr Jr HW (1986) Management of bacterial populations for foliar disease biocontrol. In: Mukerjl KG, Garg KL (Eds.) Biocontrol of Plant Diseases. Boca Raton FL. CRC Press. pp. 83-92.

Kupper KC, Fernandes NG (2002) Isolamento e seleção de Bacillus spp. para o controle de Colletotrichum acutatum em flores destacadas de lima ácida 'Tahiti'. Summa Phytopathologica 28:292-295.

Kupper KC, Fernandes NG, Goes A (2003) Controle biológico de Colletotrichum acutatum, agente causal da queda prematura dos frutos cítricos. Fitopatologia Brasileira 28:251-257.

Kupper KC, Bettiol W, Goes A, Souza PS, Bellotte JAM (2006) Biofertilizer for control of Guignardia citricarpa, the causal agent of citrus black spot. Crop Protection 25:569-573.

McQuilken MP, Whipps JM, Lynch JM (1994) Effects of water extracts of a composted manure-straw mixture on the plant pathogen Botrytis cinerea. World Journal Microbiology Biotechnology 10:20-66.

Prasad RD, Rangeshwaran R, Hegde SV, Anuroop CP (2002) Effect of soil and seed application of Trichoderma harzianum on pigeonpea wilt caused by Fusarium udum under field conditions. Crop Protection 21:293-297.

Rodrigues MBC, Andreote FD, Spósito MB, Aguillar-Vildoso CI, Araújo WL, Pizzirani-Kleiner AA (2007) Resistência a benzimidázois por Guignardia citricarpa. Pesquisa Agropecuária Brasileira 42:323327.

Sales Júnior R, Beltran R, Vicent A, Armengol J, García-Jiménez J, Medeiros EV (2007) Biological control of Monosporascus cannonballus by Chaetomium. Fitopatologia Brasileira 32:70-74.

SAS (2002) Statistical Analysis System-Getting Started with the SAS Learning Edition. Carry, NC. SAS Institute Inc.

Spósito MB, Amorim L, Belasque Junior J, Bassanezi RB, Aquino R (2004) Elaboração e validação de escala diagramática para avaliação da severidade da mancha preta em frutos cítricos. Fitopatologia Brasileira 32:81-85.

Swift M, Heal OW, Anderson JM (1979) Decomposition in terrestrial ecosystems. Studies in ecology. Oxford, UK. Blackwell Scientific. Vol. 5.

Tratch R, Bettiol W(1997)Efeito de biofertilizante sobre o crescimento micelial e a germinação de esporos de alguns fungos fitopatogênicos. Pesquisa Agropecuária Brasileira 32:1131-1139.

Yohalem DS, Nordheim EV, Andrews JH (1996) The effect of water extracts of spent mushroom compost on apple scab in the field. Phytopathology 86:914-922. 